\title{
Differences in mid-latitude stratospheric winds between reanalysis data and versus radiosonde observations at Prague
}

\author{
M. Kozubek, J. Laštovička, and P. Križan \\ Institute of Atmospheric Physics ASCR, Bocni II, 14131 Prague, Czech Republic \\ Correspondence to: M. Kozubek (kozubek.michal@ufa.cas.cz) \\ Received: 3 December 2013 - Revised: 21 February 2014 - Accepted: 2 March 2014 - Published: 11 April 2014
}

\begin{abstract}
Reanalysis data are very useful for studying the stratosphere. They can be used for analysis of long-term trends (temperature, wind speed, humidity, etc.) or analysis of global atmospheric dynamics, etc. There are various reanalysis projects that provide outputs which are not identical. In this paper, we mutually compare three of them, ERA-40, ERA-Interim and NCEP/NCAR, and compare them with balloon radiosonde observations from Prague, Port Hardy and Valentia stations. This comparison is done for wind speed and direction at pressure levels 100 and $10 \mathrm{hPa}$ and for various periods between 1957 and 2009. The results show that the differences between reanalysis vary. Wind speed data from all three analyses reasonably agree except for the $10 \mathrm{hPa}$ historical data before 1966 and particularly ERA-40 data at the end of the data series (1998-2001). The quality of the ERA-40 $10 \mathrm{hPa}$ stratospheric wind data has been proven to be substantially worse over the last four ERA-40 years of 1998 2001 (2002) compared to previous years, both in wind speed and wind direction. The reanalysis data results are compared with radiosonde observations from Prague, Port Hardy and Valentia stations at $10 \mathrm{hPa}$ for the months of February between 1989 and 2009. The results show that there are sometimes surprisingly large differences, more for ERA-Interim versus Prague measurements. Differences in wind direction greater than $45^{\circ}$ (outliers) between the reanalysis data and Prague observations in wind direction occur in Februaries predominantly when winds in Prague are in "minor" sectors, such as north, northeast and east (easterlies), whereas "major" sectors, particularly the dominant W (westerlies) wind sector, exhibit almost no outliers.
\end{abstract}

Keywords. Meteorology and atmospheric dynamics (middle atmosphere dynamics)

\section{Introduction}

Study of wind characteristics (time development, trends and changes) in the stratosphere is very difficult due to the absence of a sufficient number of reliable direct measurements. Therefore, reanalysed data are used to study the wind in the stratosphere. To make the observational data series regularly gridded in space and time and to suppress various outliers in local observational data, various data sets were reanalysed together and the "reanalysis" was created, but the reanalysis results are a combination of numerical weather forecast and observations.

The reanalyses widely used in the past, which cover different periods, are NCEP/NCAR-I (since 1948, Kalnay et al., 1996; Kistler et al., 2001), ERA-40 (1958-2002, Uppala et al., 2005), JRA-25 (1979-2007, Onogi et al., 2007), ERAInterim (since 1989, Dee et al., 2011), NCEP/DOE (since 1979, Kanamitsu et al., 2002) and MERRA-NASA (since 1979, Reichle, 2012). They cover various time intervals, have different resolutions and apply different methods of data assimilation (Courtier et al., 1998; Parish and Derber, 1992). Errors and inconsistencies in the assimilation system or in the assimilated data can result in step changes (Brönnimann et al., 2009; Screen and Simmonds, 2011).

Some discrepancies between reanalyses (differences in multidecadal trends of sea level pressure (SLP), $500 \mathrm{hPa}$ height, and temperatures at $2 \mathrm{~m}$ or $500 \mathrm{hPa}$ ) do occur in the troposphere and these have been investigated (e.g. Akperov and Mokhov, 2010; Birner, 2010; Greatbatch and Rong, 2006; Simmons et al., 2004; Trigo, 2006; Watarai and Tanaka, 2007; Žagar et al., 2009; Zhao and Li, 2006). Wind field differences were found between ERA-40, NCEP/NCAR and NCEP/DOE reanalysis over 1979-2001 by evaluating 
the atmospheric excitation of the Earth's rotation (Masaki, 2008).

In contrast to the troposphere, only a few studies were done of differences in the stratosphere. Iwasaki et al. (2009) studied the Brewer-Dobson circulation (BDC), the mean meridional stratospheric circulation derived from JRA-25, ERA-40, ERA-Interim, NCEP/NCAR-1 and NCEP/DOE. Considerable discrepancies among reanalyses were found, particularly for low latitudes. Interannual variability of BDC in winter is coincident among the reanalyses, but yearly trends are not reliably observed due to a large diversity among the reanalyses. Lehmannn and Nevir (2012) analysed zonal winds from ERA-40 and NCEP/NCAR-1 in the troposphere and lower stratosphere over the tropical Pacific. They found that NCEP/NCAR better reproduced the observed wind in the troposphere, whereas ERA-40 was better in the lower stratosphere. Paek and Huang (2012) compared the interannual variability of atmospheric angular momentum calculated from eight reanalysis data sets for the post-1979 era. They found a close agreement among almost all reanalysis data sets except for CR20, where a problem was caused by stratospheric wind and the absence of QBO. They claim that the most significant discrepancies among the reanalysis data sets are in the long-term mean and long-term trend. Martineau and Son (2010) tested ERA, JRA-25, NASAMERRA, NCEP-DOE and NCEP/NCAR-1 data for stratospheric vortex weakening or intensification events during Northern Hemisphere winters. For the 2009 sudden stratospheric warming (SSW) they found locally substantial biases in the $10 \mathrm{hPa}$ level temperatures, especially for JRA-25, but biases disappeared in the lower stratosphere and troposphere. Thus there are differences in some above-mentioned parameters between reanalyses in the stratosphere. Therefore there might also be differences in winds in the stratosphere, which should be inspected.

As far as we know, no direct comparison between various reanalyses has been made for stratospheric winds in the northern extratropical latitudes; this is the main aim of this paper. Section 2 deals with data and methods used for comparison. Results are described in Sect. 3. The paper is closed by a brief discussion in Sect. 4 and conclusions in Sect. 5 .

\section{Data and method}

We compare the NCEP/NCAR-1 (further on NCEP/NCAR), ERA-40 and ERA-Interim reanalyses. The NCEP/NCAR reanalysis was described in detail by Kistler et al. (2001). This reanalysis provides data from 1948 onwards, but data is more reliable from 1957 onwards, when the first upper-air observations were established, and from 1979 onwards, due to the beginning of satellite date assimilation. Data is available within the $2.5^{\circ}$ by $2.5^{\circ}$ grid box at 00:00, 06:00, 12:00 and 18:00 UTC. The vertical resolution is 28 levels, with the top of the model at $2.7 \mathrm{hPa}$. The NCEP/NCAR analysis system efficiently assimilates upper-air observations, but it is only marginally influenced by surface observations because model orography differs from reality (Kistler et al., 2001). According to Kistler et al. (2001), there are some human errors which affected the reanalysis.

A detailed description of ERA-40 is given by Uppala et al. (2005). The ERA-40 reanalysis provides data from 1957 to August 2002. Satellite data has been assimilated since 1979. Reanalysis data is available in the $1.125^{\circ}$ by $1.125^{\circ}$ grid box at 00:00, 06:00, 12:00 and 18:00 UTC, but we used a horizontal resolution of $2.5^{\circ} \times 2.5^{\circ}$, which contains the $1.125^{\circ} \times 1.125^{\circ}$ grid information in a more compact form, to get a comparison with NCEP/NCAR reanalysis. Vertical resolution is 60 levels, with the top of the model at $0.1 \mathrm{hPa}$; it was increased in the stratosphere compared with ERA-15. Uppala et al. (2005) described errors and problems which influenced the output of the model (reanalyses), but the code was corrected as much as possible. Uppala et al. (2005) found too strong a Brewer-Dobson circulation in ERA-40 and biases in the temperature and wind structure in the upper stratosphere. To avoid the influence of the latter, we study only the lower and middle stratosphere; the impact of the former hopefully will not be very important, but it should be considered in interpretations of the results.

The other product of ECMWF is the ERA-Interim reanalysis. Its full description can be found in Berrisford et al. (2009) and Dee et al. (2011). This reanalysis is presented as an improved version of ERA-40. Data is available from 1979 to the present at the resolution $0.75^{\circ}$ to $0.75^{\circ}$ at the same times as the ERA-40 reanalysis. The vertical resolution is identical to that of ERA-40. We used data with the horizontal resolution $1.5^{\circ} \times 1.5^{\circ}$, which is a compact form of the $0.75^{\circ} \times 0.75^{\circ}$ resolution, as results published until recently were based on this resolution. According to Berrisford et al. (2009), ERAInterim and ERA-40 use (with some exceptions) as input prior to 2002 the same observations.

From all three reanalysis we use the Northern Hemisphere middle and high latitude data from $30^{\circ} \mathrm{N}$ to $80^{\circ} \mathrm{N}$ in $2.5^{\circ} \times 2.5^{\circ}\left(\right.$ ERA-40, NCEP/NCAR) or $1.5^{\circ} \times 1.5^{\circ}$ (ERAInterim) horizontal resolution and at 00:00 UTC. Wind speed and direction was calculated from the gridded meridional and zonal components of wind. The wind is not a quantity primarily computed by reanalysis models, it is a quantity derived from these primary quantities and, therefore, we may expect larger errors in winds than in primary quantities (Kistler et al., 2001). Here we focus on the middle latitude of $52.5^{\circ} \mathrm{N}$, that latitude which was used by Laštovička et al. (2010) due to the availability of mesopause region winds (heights $\sim 90-95 \mathrm{~km}$ ), and $50^{\circ} \mathrm{N}$, where Prague-Libus observations are available. The results from other latitudes are only very briefly mentioned in this paper.

Data are analysed in several ways. The first one is called "wind distribution". Distributions of wind speeds and directions are constructed. NCEP/NCAR and ERA-40 reanalysis are analysed. Typically, each year is separated into 
two seasons, summer season (from April to September) and winter season (from October to March), but, hereafter, we present more often the winter season results, because winds are stronger in the winter. The whole period (1957-2002) is separated into two sub-periods (1957-1989 and 1990-2002). The sub-periods were chosen in accordance with the change in trends of yearly averaged winds in the mesopause region (Laštovička et al., 2008). The selected latitude of $52.5^{\circ} \mathrm{N}$ is separated into four sectors $\left(0-90^{\circ} \mathrm{E}-\right.$ European sector, 90 $180^{\circ} \mathrm{E}$ - Asian sector, $180-300^{\circ} \mathrm{W}$ - Pacific-American sector, and $300-360^{\circ} \mathrm{E}-$ Atlantic sector). The wind speed and direction are analysed for pressure levels 10,100 and $500 \mathrm{hPa}$ (for comparison), which are considered representative of the middle and lower stratosphere and middle troposphere. As a result we use the seasonal average through the whole subperiod displayed as an occurrence frequency of wind speeds in each interval of speeds (see Fig. 1). Results of wind speed are separated into intervals with steps of $2.5 \mathrm{~m} \mathrm{~s}^{-1}$.

The second way we analyse data is called "time development". We calculate annual or monthly average values throughout the whole period (1958-2008). The latitude of $52.5^{\circ} \mathrm{N}$ is again divided into four sectors as above. Absolute $\left(\mathrm{m} \mathrm{s}^{-1}\right)$ differences in individual years between each reanalysis for the selected sector or single grid points and their time development are searched for. As for monthly values, the month of February is selected for analysis because winds are typically very strong (relative errors should be smaller than for weak winds) and differences are more pronounced than in other months. Some results for May, August and November are presented for comparison.

For analysis in individual grid points we again use the February data. Differences between reanalyses and also differences between reanalyses and radiosonde data in grid points are investigated on a monthly and, partly, on a daily basis for the period 1989-2009, both for wind speed and wind directions (results of wind direction are separated into standard wind roses). We looked for stations near grid points of reanalysis near latitudes $52.5^{\circ} \mathrm{N}$ and $50^{\circ} \mathrm{N}$, with good quality and sufficient quantity of available continuous data over a long period of time. Therefore Prague-Libus was selected $\left(50^{\circ} \mathrm{N}, 15^{\circ} \mathrm{E}\right.$ grid point - there is no difference between the overall behaviour of stratospheric winds between $50^{\circ} \mathrm{N}$ and $52.5^{\circ} \mathrm{N}$ ) as a European (and Czech) station influenced by the Atlantic Ocean. The other station is Port Hardy $\left(50.5^{\circ} \mathrm{N} 127.5^{\circ} \mathrm{W}\right)$ located on the west coast of the USA, which is influenced by the Pacific Ocean, and Valentia observatory $\left(51.9^{\circ} \mathrm{N}, 10.15^{\circ} \mathrm{W}\right)$, which is located in the west of Ireland on the Atlantic coast. Data are taken from the website: http://www1.ncdc.noaa.gov/pub/data/igra/ derived/ for Port Hardy and the Valentia station, and from the Czech Hydrometeorological Institute for Prague. It should be mentioned that we did not find any other station fulfilling the criteria for station selection (near grid point of reanalyses at $50-52.5^{\circ} \mathrm{N}$, good quality data and a long data record).

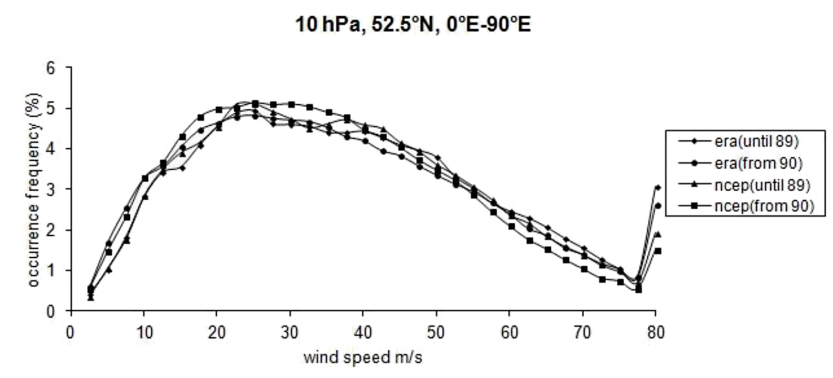

$100 \mathrm{hPa}, 52.5^{\circ} \mathrm{N}, 0^{\circ} \mathrm{E}-90^{\circ} \mathrm{E}$

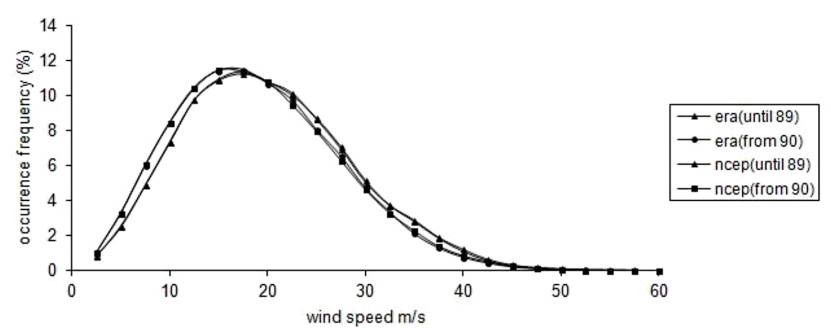

Fig. 1. Zonal wind speed average occurrence frequency for ERA40 and NCEP/NCAR reanalyses, $52.5^{\circ} \mathrm{N}$, sector $0-90^{\circ} \mathrm{E}, 100 \mathrm{hPa}$ (top panel) and $10 \mathrm{hPa}$ (bottom panel) for two periods of 1958-1989 (until 1989) and 1990-2001 (from 1990), winter half of the year. The value for $80 \mathrm{~m} \mathrm{~s}^{-1}$ means the sum of wind speeds $\geq 80 \mathrm{~m} \mathrm{~s}^{-1}$. ERA-40 and NCEP/NCAR curves are indistinguishably identical for $100 \mathrm{hPa}$, both intervals.

\section{Results}

\subsection{Wind distribution results}

The wind distribution results for the European sector 0-90 $\mathrm{E}$ (Fig. 1) show that there are almost no differences in the overall wind speed distribution between NCEP/NCAR and ERA40 at the $100 \mathrm{hPa}$ level for the European sector at $52.5^{\circ} \mathrm{N}$ for the winter half of the year (October-March). However, for $10 \mathrm{hPa}$, Fig. 1 reveals larger differences, especially for the period after 1990. The difference in occurrence frequency near the wind speed of $30 \mathrm{~m} \mathrm{~s}^{-1}$ reaches up to almost $14 \%$ of the ERA-40 value for $10 \mathrm{hPa}$. The period before 1990 (19581990) reveals a smaller difference of no more than $5 \%$ of the ERA-40 value for $10 \mathrm{hPa}$. The differences for other sectors and other latitudes (not shown here) are similar to this sector. It is useful to note that the maximum occurrence frequency of wind speed is about $17 \mathrm{~m} \mathrm{~s}^{-1}$ at $100 \mathrm{hPa}$, but at $10 \mathrm{hPa}$ there is a broad, flat maximum between about 20 and $32.5 \mathrm{~m} \mathrm{~s}^{-1}$ (Fig. 1). There are some differences between the wind strength of the first and the second periods for both pressure levels. In the first period (until 1989) the winds are a little bit stronger than in the second period (from 1990), see Fig. 1. For $10 \mathrm{hPa}$ there are similar differences between ERA-40 and NCEP/NCAR for other latitudes as those for latitude of $52.5^{\circ} \mathrm{N}$. Winds are again stronger for the period "until 89" (including 1989) than for period "from 1990" (1990 


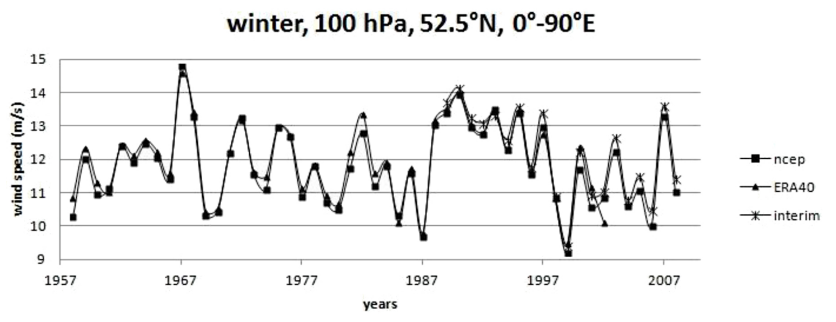

winter, $10 \mathrm{hPa}, 52.5^{\circ} \mathrm{N}, 0^{\circ}-90^{\circ} \mathrm{E}$

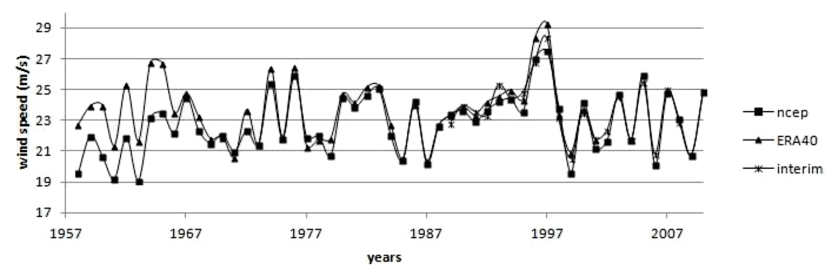

Fig. 2. Winter (October-March) averages for $52.5^{\circ} \mathrm{N}$, sector 0 $90^{\circ} \mathrm{E}, 100 \mathrm{hPa}$ (top) and $10 \mathrm{hPa}$ (bottom). Where data of more than one reanalysis overlap, only one line is displayed.

onwards), especially for high latitudes (e.g. $72.5^{\circ} \mathrm{N}$ of the European sector).

\subsection{Time development of parameters}

Next we turn to the time development of parameters. Figure 2 displays winter (October-March) averages of wind speed for the period 1958-2010, European sector. Some systematic differences (a bias of about $4 \mathrm{~m} \mathrm{~s}^{-1}$ for $10 \mathrm{hPa}$ ) exist at the beginning of that period until 1966, but we have to note that satellite data has only been implemented since 1979. After 1966 the results for all reanalyses agree reasonably with each other at both pressure levels.

Figure 3 shows differences between wind speeds for monthly (February, May, August and November) averages for the Atlantic sector at $100 \mathrm{hPa}$. The differences between NCEP/NCAR, ERA-40 and ERA-Interim are small, generally within about $\pm 1 \mathrm{~m} \mathrm{~s}^{-1}$, revealing a good agreement between these three reanalyses for all four analysed months, with only one exception, in May 2001, which looks like an outlier in the NCEP/NCAR data. The small differences are sometimes positive, sometimes negative and no clear bias can be found.

Figure 4 shows the same results as Fig. 3 but for the $10 \mathrm{hPa}$ level. In the summer half of the year (May and August), winds from all three reanalyses agree well each other, within about $\pm 2 \mathrm{~m} \mathrm{~s}^{-1}$, mostly within $\pm 1 \mathrm{~m} \mathrm{~s}^{-1}$, except for ERA-40 in the years 1998-2001 (this problem is discussed in Sect. 3.4), when differences reach more than $\pm 10 \mathrm{~m} \mathrm{~s}^{-1}$ (much stronger wind in ERA-40) and are statistically significant at $95 \%$ level, and the NCEP/NCAR anomaly in May 2001 observed also at $100 \mathrm{hPa}$. There are some differences, up to about $\pm 5-7 \mathrm{~m} \mathrm{~s}^{-1}$ in the winter half of the year (February and November, statistically significant at $95 \%$
February, $52.5^{\circ} \mathrm{N}, 300^{\circ}-360^{\circ} \mathrm{E}$

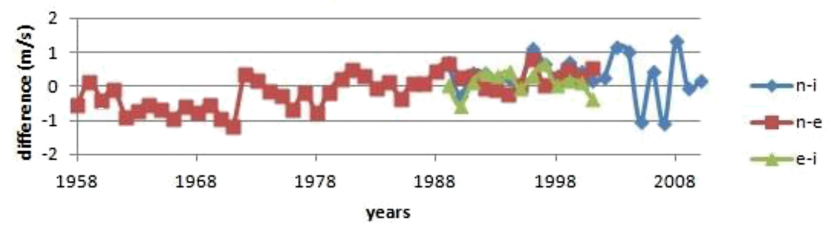

May, $52.5^{\circ} \mathrm{N}, 300^{\circ}-360^{\circ} \mathrm{E}$

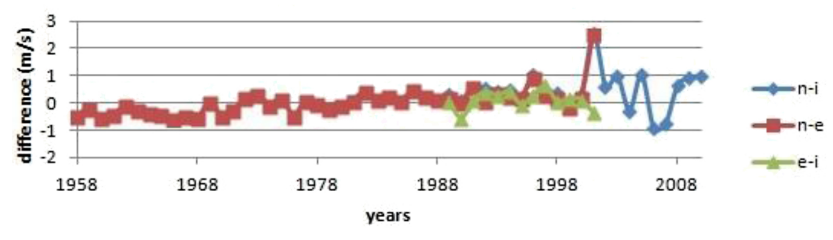

August, $52.5^{\circ} \mathrm{N}, 300^{\circ}-360^{\circ} \mathrm{E}$

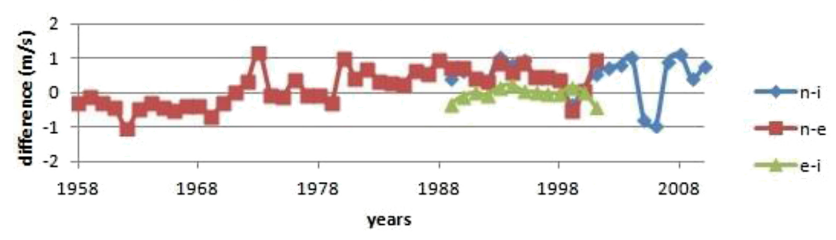

November, $52.5^{\circ} \mathrm{N}, 300^{\circ}-360^{\circ} \mathrm{E}$

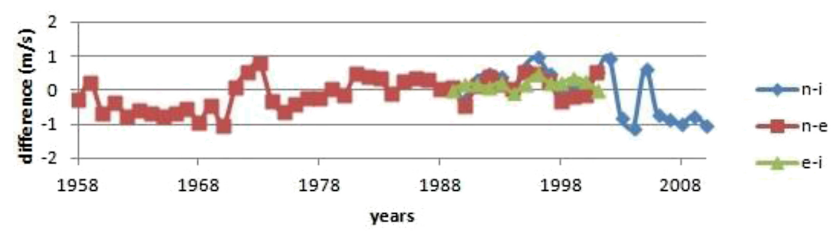

Fig. 3. Differences between reanalysis for February, May, August and November averages, $52.5^{\circ} \mathrm{N}$, sector $300-360^{\circ} \mathrm{W}$ for $100 \mathrm{hPa}$; e - ERA-40, n - NCEP/NCAR, I - ERA-Interim. Where differences overlap, only one colour is displayed.

level, occurring mainly at the beginning of the period), between NCEP/NCAR and ERA-40. The problem with the years 1998-2001 is again well expressed.

We did the same analysis for the pressure level $500 \mathrm{hPa}$ over 1989-2010. The agreement between all three reanalyses is remarkably good for the whole period 1989-2010.

\subsection{Comparison of reanalyses with radiosonde data}

Until now we have only compared reanalyses with each other. However, this does not provide an answer to the question of which reanalysis is more relevant to observations. Therefore a comparison of reanalysis with radiosonde data is needed. The observations are assimilated into reanalysis (using different assimilation techniques). However, observations at individual stations and reanalyses could be considered as independent data sets. We made a comparison between three stations located close to grid points of reanalysis, 
February, $52.5^{\circ} \mathrm{N}, 300^{\circ}-360^{\circ} \mathrm{E}$

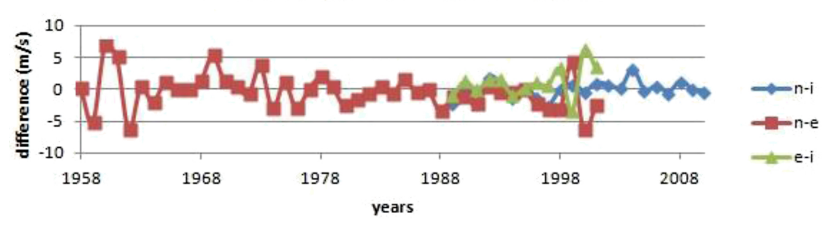

May, $52.5^{\circ} \mathrm{N}, 300^{\circ}-360^{\circ} \mathrm{E}$

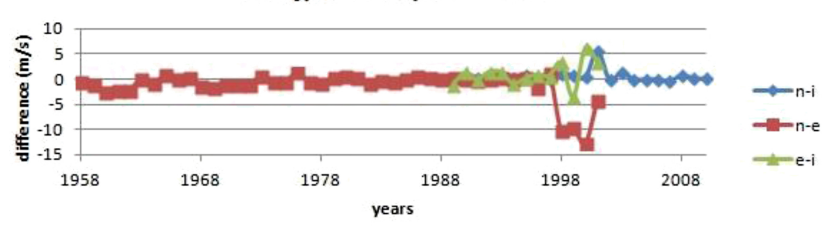

August, $52.5^{\circ} \mathrm{N}, 300^{\circ}-360^{\circ} \mathrm{E}$

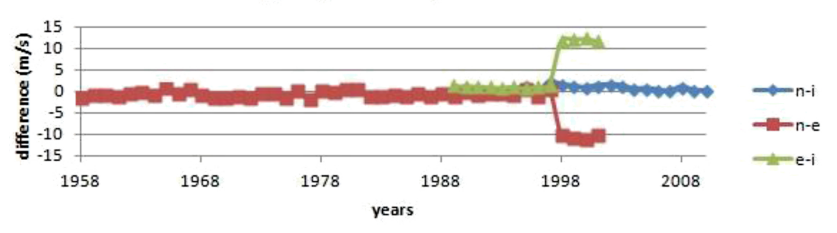

November, $52.5^{\circ} \mathrm{N}, 300^{\circ}-360^{\circ} \mathrm{E}$

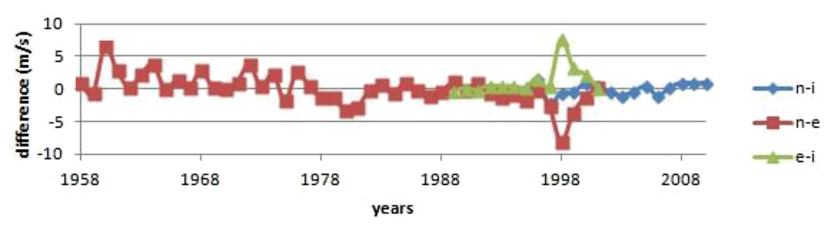

Fig. 4. Differences between reanalysis for February, May, August and November averages, $52.5^{\circ} \mathrm{N}$, sector $300-360^{\circ} \mathrm{W}$ for $10 \mathrm{hPa}$; e - ERA-40, $\mathrm{n}$ - NCEP/NCAR, I - ERA-Interim. Where differences overlap, only one colour is displayed.

Prague-Libus $\left(50^{\circ} \mathrm{N}, 15^{\circ} \mathrm{E}\right)$, Port Hardy $\left(50.5^{\circ} \mathrm{N} 127.5^{\circ} \mathrm{W}\right)$ and Valentia $\left(51.9^{\circ} \mathrm{N}, 10.15^{\circ} \mathrm{W}\right)$ for all three reanalyses over the period 1989-2009.

Data from reanalysis and from the radiosonde stations used in Figs. 5-10 are for $10 \mathrm{hPa}$ and 00:00 UTC. Monthly average values are calculated only from days where station measurements are available. Figure 5 displays differences in wind speeds between reanalysis data and Prague observations for February, May, August and November of individual years at $10 \mathrm{hPa}$. The best agreement can be found in May (differences within $\pm 2 \mathrm{~m} \mathrm{~s}^{-1}$ ) and August (differences within $\pm 3 \mathrm{~m} \mathrm{~s}^{-1}$ except for August 1991). The differences are statistically significant at the $95 \%$ level in 1990, 1993, 1994, 1997, 1998 and 2009 for May and 1991 for August). The "outlier" difference between all reanalyses and Prague in August $1991\left(5-6 \mathrm{~m} \mathrm{~s}^{-1}\right)$ is probably caused by a problem with observations in Prague (reanalyses agree with each other). The differences for February between NCEP/NCAR and ERA-40 versus Prague-Libus are very similar and vary from $8 \mathrm{~m} \mathrm{~s}^{-1}$ (1990) to less than $1 \mathrm{~m} \mathrm{~s}^{-1}(1989,1999$,
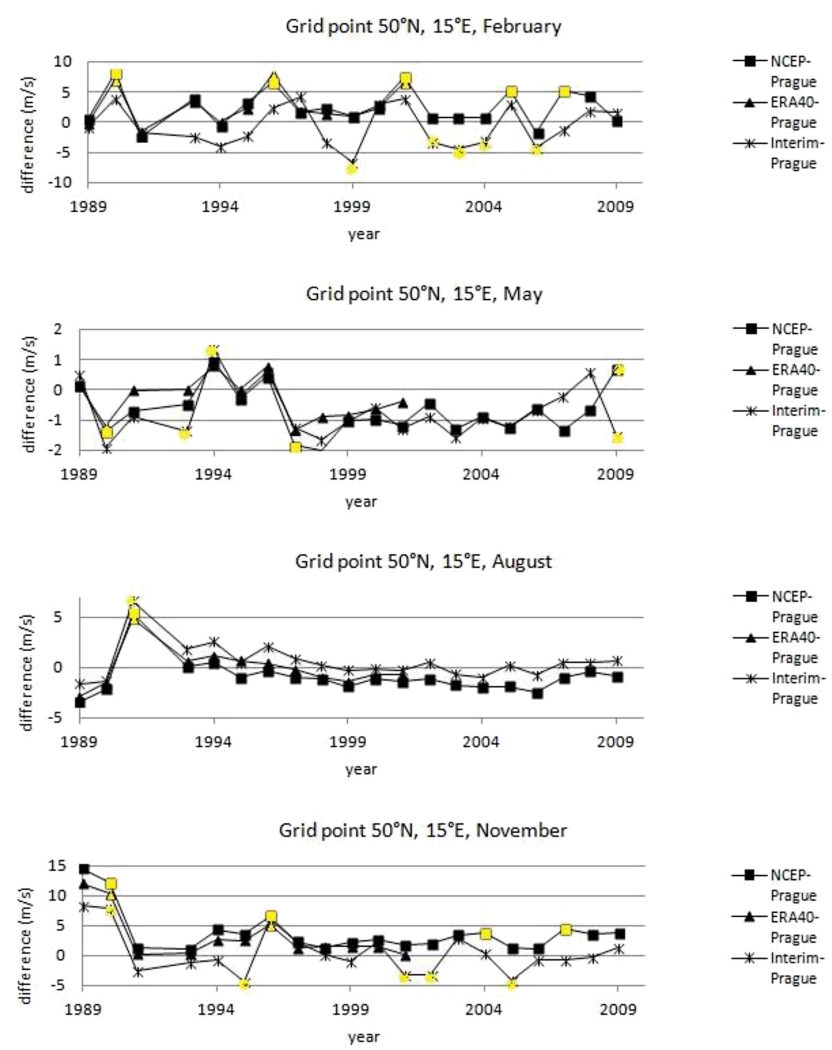

Fig. 5. Differences in February, May, August and November average wind speeds between reanalysis at grid point $50^{\circ} \mathrm{N}$ (ERA-40, NCEP) or $49.5^{\circ} \mathrm{N}$ (ERA-Interim), $15^{\circ} \mathrm{E}$ and Prague-Libus station $\left(50^{\circ} \mathrm{N}, 15^{\circ} \mathrm{E}\right)$ at $10 \mathrm{hPa}$. Yellow full circles mean differences statistically significant at $95 \%$ level.

2002-2004). For ERA-Interim (grid point $49.5^{\circ} \mathrm{N}, 15^{\circ} \mathrm{E}$ ) the differences are dissimilar. The difference is slightly larger than $6 \mathrm{~m} \mathrm{~s}^{-1}$ only in 1999 (statistically significant difference); in other years it is no more than $\pm 4 \mathrm{~m} \mathrm{~s}^{-1}$ (statistically significant differences in 1990, 1996, 2001-2006). ERA-40 seems to agree with Prague observations a little bit better than NCEP/NCAR, but the difference is imperceptible (less than $1 \mathrm{~m} \mathrm{~s}^{-1}$ ). In November we can see a similar problem as in February. We exclude from analysis years 1989 and 1990, where the difference seems to be largely caused by Prague data. The differences between NCEP/NCAR and ERA-40 versus Prague-Libus are similar (up to $5 \mathrm{~m} \mathrm{~s}^{-1}$ in 1996) and between ERA-Interim and Prague are dissimilar as in February. There is a systematic positive bias in November and February for NCEP/NCAR and ERA-40 versus Prague observations (about $2.5 \mathrm{~m} \mathrm{~s}^{-1}$ ). In May and August biases are statistically insignificant (slightly negative for NCEP/NCAR and ERA-40, slightly positive for ERA-Interim). In some years, like 1989, 1990, 1991 or 2001, when differences in all three reanalyses from Prague observations are large and relatively similar, the main part of the difference is likely caused by the Prague data due to inaccuracies or local effects 


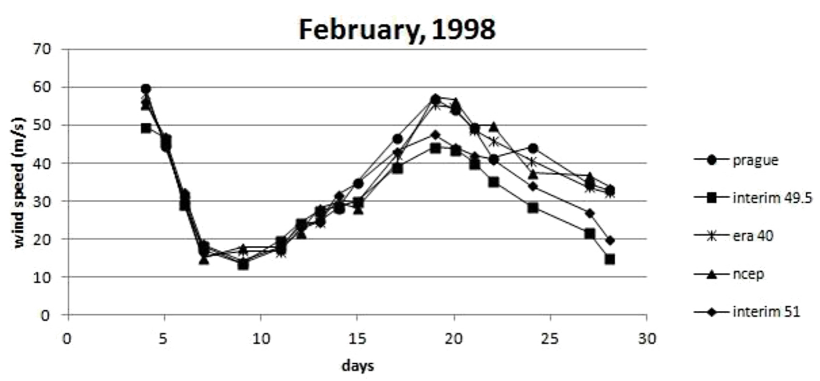

Fig. 6. Time development of ERA-40, $\operatorname{NCEP}\left(50^{\circ} \mathrm{N}, 15^{\circ} \mathrm{E}\right)$, ERAInterim $\left(51^{\circ} \mathrm{N}\right.$ and $\left.49.5^{\circ} \mathrm{N}, 15^{\circ} \mathrm{E}\right)$ and Prague-Libus wind speeds for February 1998 at $10 \mathrm{hPa}$.

or maybe the non-representativeness of short-time soundings for general stratospheric conditions. However, in years when differences are large but quite different for ERA-Interim and the two other reanalyses, like in 1995 or 1999, the problem is in reanalysis. We can conclude that the problem, i.e. larger differences, occurs mainly in the winter half of the year.

Figure 6 shows an example of one particular month, the time development of wind speed for February 1998 (just the days when radiosonde observations are available). It is obvious that the ERA-Interim reanalysis (for both $49.5^{\circ} \mathrm{N}$ and $51^{\circ} \mathrm{N}, 15^{\circ} \mathrm{E}$ ) somewhat underestimates wind speed during the last ten days of the month (slightly less for $51^{\circ} \mathrm{N}$ ERA-Interim data). Two other reanalyses agree reasonably well with the Prague data, ERA-40 slightly better than NCEP/NCAR. However, until February 17 the agreement of all reanalyses with observations is very good, and on 15 February ERA-Interim $\left(51^{\circ} \mathrm{N}\right)$ agrees best with observations. The main result of Fig. 6 is that on a timescale of days, none of the reanalyses is for all days universally the best reanalysis when compared with Prague data.

A similar analysis as for Prague in Fig. 5 has been done for the Port Hardy station, but only for February (Fig. 7). The results reveal much less agreement between this station and all three reanalyses than for Prague. Figure 7 shows that the differences between all three reanalyses versus Port Hardy data reach up to $40 \mathrm{~m} \mathrm{~s}^{-1}(1993,1996$ and 2005) and all differences are significant. In most years all three reanalyses provide substantially higher wind speeds than Port Hardy radiosondes. This indicates that the discrepancy is very probably with the Port Hardy data themselves, perhaps due to inaccuracies in measurements but more probably due to local effects attributable to the vicinity of high mountains or other local differences. Port Hardy seems to be an example of a station which may be unsuitable for testing reanalysis of stratospheric winds. On the other hand, reanalysis was created in order to suppress and/or correct the influence of such stations. The results for Valentia are not shown since the results indicate that this station is also unsuitable for testing of reanalysis of the stratospheric winds.
Figure 8 reveals the overall comparison of reanalyses and Prague radiosonde data for February in terms of non-outlier value occurrence frequency. The outliers hereafter in the paper mean the days with differences between Prague and reanalysis data larger than $15 \%$ for wind speed, and/or larger than $45^{\circ}$ for wind direction. We have been working hereafter predominantly with wind direction outliers. In Fig. 8, wind speeds are separated into intervals of $5 \mathrm{~m} \mathrm{~s}^{-1}$ and wind directions into the standard eight sectors. The top panel shows the number of non-outliers for wind speed, and the bottom panel for wind direction. The top panel reveals that the agreement between Prague and reanalysis is worse for lower speeds (up to $25 \mathrm{~m} \mathrm{~s}^{-1}$ ) than for higher speeds, as expected with respect to the limit being in percentage. The worst agreement is for ERA-Interim reanalysis for almost all wind speeds and the best agreement is for NCEP-NCAR reanalysis, at least for high wind speeds. The bottom panel (wind direction) reveals the worst agreement for minor directions ( $\mathrm{E}$ and $\mathrm{S}$ for all three reanalyses, N and NE for ERA-Interim, SE and SW for ERA-40). In general we can say that for wind direction ERA-Interim agrees better with observations than ERA-40 in terms of outlier occurrence.

Figure 8 gives two interesting results. First, even though Prague-Libus is located in the Central Europe sector, the number of outliers (difference in direction larger than $45^{\circ}$, in speed larger than $15 \%$ ) is smallest for NCEP/NCAR, not for ERA-40, both for wind speed as well as direction. Second, in the E-sector all reanalyses reveal more than $50 \%$ of wind directions to be outliers, even with the limit of $45^{\circ}$, which is equal to the width of the sector.

Figure 8 shows that the occurrence of large differences in wind direction between reanalysis and Prague-Libus is not negligible. Therefore it is of some interest to look at individual outliers in wind direction (where the difference between wind directions from Prague measurements and reanalysis is more than $45^{\circ}$ - hereafter "outlier" refers to a wind direction outlier). They are summarised in Table 1 for Februaries and the $10 \mathrm{hPa}$ level. The number of outliers is smallest for NCEP/NCAR, much larger for ERA-40, and medium for ERA-Interim. The total number of days with outliers in at least one reanalysis is 54; out of them NCEP/NCAR outliers occur on 11 days, ERA-Interim outliers on 27 days and ERA-40 outliers on 37 days (Table 2). All reanalyses exhibit outliers simultaneously on only 4 days (on two of these days differences among reanalyses are very large), whereas on 37 days only one reanalysis reveals an outlier. The overall number of February days used in analysis is 226, those with outliers 54 . This means that outliers for at least one reanalysis occur in $24 \%$ of days, which is a surprisingly high occurrence frequency. In most outlier days the outliers are revealed by only one reanalysis, which supports the idea that problems with reanalysis, not with Prague observations, are the main source of outliers.

The number of outlier days (in terms of wind direction) in February varies substantially from year to year (Table 1), 
Table 1. All days with differences between reanalyses and Prague-Libus at $10 \mathrm{hPa}$ higher than $45^{\circ}$ (W - westerlies), Prague-Libus wind speed, radiosonde position in $10 \mathrm{hPa}$, February, 1989-2001, for grid point $50^{\circ} \mathrm{N}, 15^{\circ} \mathrm{E}$.

\begin{tabular}{|c|c|c|c|c|c|c|c|c|c|}
\hline \multirow[b]{2}{*}{ Year } & \multirow[b]{2}{*}{ Month } & \multirow[b]{2}{*}{ Day } & \multirow[b]{2}{*}{ Prague } & \multicolumn{3}{|c|}{ Difference } & \multirow[b]{2}{*}{ Pr-wind $\left(\mathrm{m} \mathrm{s}^{-1}\right)$} & \multicolumn{2}{|c|}{ Radiosonde position in $10 \mathrm{hPa}$} \\
\hline & & & & ERA40-Pr & NCEP-Pr & ERAIn-Pr & & Latitude & Longitude \\
\hline 1989 & 2 & 9 & ne & & 92.6 & 46.4 & 10.6 & 50.11 & 14.75 \\
\hline 1989 & 2 & 11 & $\mathrm{e}$ & 90 & & 58.9 & 47.7 & 49.94 & 14.16 \\
\hline 1989 & 2 & 13 & $\mathrm{e}$ & 67.1 & 61.1 & & 29 & 49.9 & 14.9 \\
\hline 1989 & 2 & 15 & $\mathrm{e}$ & & 85.2 & 59.5 & 50 & 49.39 & 13.83 \\
\hline 1989 & 2 & 19 & $\mathrm{e}$ & 46.1 & & & 33 & 49.67 & 14.69 \\
\hline 1990 & 2 & 24 & $\mathrm{n}$ & & & 291.2 & 5.1 & 50 & 14.97 \\
\hline 1993 & 2 & 25 & $\mathrm{w}$ & & & 47.9 & 36.3 & 49.41 & 14.82 \\
\hline 1994 & 2 & 6 & $\mathrm{n}$ & & & 51 & 15.3 & 50.13 & 14.83 \\
\hline 1994 & 2 & 12 & ne & & & 107.9 & 20.7 & 49.53 & 14.39 \\
\hline 1994 & 2 & 13 & $\mathrm{n}$ & & & 148.1 & 24.5 & 49.3 & 14.34 \\
\hline 1994 & 2 & 20 & ne & & & 119.3 & 18.1 & 49.91 & 14.68 \\
\hline 1994 & 2 & 21 & sw & & & 128.5 & 11.6 & 50.38 & 14.85 \\
\hline 1994 & 2 & 24 & $\mathrm{~s}$ & & 45.9 & 52.5 & 43.6 & 50.14 & 15.75 \\
\hline 1995 & 2 & 6 & $\mathrm{n}$ & & & 49.2 & 21.9 & 49.16 & 14.71 \\
\hline 1995 & 2 & 7 & w & 199.6 & 242.4 & 96 & 4.5 & 49.48 & 14.98 \\
\hline 1997 & 2 & 1 & ne & & & 116.1 & 13.8 & 49.3 & 14.68 \\
\hline 1997 & 2 & 2 & $\mathrm{e}$ & & 101.3 & & 8.6 & 49.53 & 14.68 \\
\hline 1998 & 2 & 11 & sw & 62.4 & & & 17.5 & & \\
\hline 1998 & 2 & 24 & nw & 56.1 & & & 44.2 & & \\
\hline 1998 & 2 & 27 & nw & 109.2 & & & 34.6 & & \\
\hline 1998 & 2 & 28 & nw & 77.1 & & & 32.9 & & \\
\hline 1999 & 2 & 2 & nw & 62.2 & & & 16.6 & & \\
\hline 1999 & 2 & 3 & nw & 74.2 & & & 22.1 & & \\
\hline 1999 & 2 & 9 & sw & 48 & & & 65.1 & & \\
\hline 1999 & 2 & 11 & sw & 60.6 & & & 85.9 & & \\
\hline 1999 & 2 & 23 & sw & 54.1 & & & 40.3 & & \\
\hline 1999 & 2 & 24 & sw & 63.4 & & & 51.8 & & \\
\hline 1999 & 2 & 25 & sw & 90.4 & & & 55.3 & & \\
\hline 1999 & 2 & 26 & sw & 115.3 & & & 44.8 & & \\
\hline 1999 & 2 & 27 & sw & 111.7 & & & 41.3 & & \\
\hline 1999 & 2 & 28 & sw & 78.4 & & & 32.5 & & \\
\hline 2000 & 2 & 8 & nw & 108.9 & & & 54.5 & & \\
\hline 2000 & 2 & 9 & nw & 97.4 & & & 33.7 & & \\
\hline 2000 & 2 & 10 & nw & 66.6 & & 54.7 & 13.2 & 49.5 & 14.93 \\
\hline 2000 & 2 & 11 & sw & 87.3 & & & 17 & & \\
\hline 2000 & 2 & 12 & sw & 78.3 & & & 16.3 & & \\
\hline 2000 & 2 & 13 & sw & 102.2 & & 49.2 & 18.5 & 49.52 & 14.86 \\
\hline 2000 & 2 & 14 & $\mathrm{n}$ & 85.7 & & 66.6 & 5.2 & 49.6 & 15.47 \\
\hline 2000 & 2 & 15 & ne & & 58 & 239.4 & 3.1 & 49.62 & 15.05 \\
\hline 2000 & 2 & 16 & sw & 128.1 & & 64.4 & 15.6 & 50.27 & 15.58 \\
\hline 2000 & 2 & 17 & $\mathrm{~s}$ & 132.5 & & & 25.5 & & \\
\hline 2000 & 2 & 21 & nw & 65.9 & & & 15.6 & & \\
\hline 2000 & 2 & 22 & nw & 83.8 & & 48 & 10.1 & 49.87 & 15.03 \\
\hline 2000 & 2 & 27 & sw & 73.1 & & & 34.4 & & \\
\hline 2001 & 2 & 18 & sw & 50.6 & & 77.7 & 15.1 & 50.07 & 14.68 \\
\hline 2001 & 2 & 19 & se & 101.4 & & & 19.9 & & \\
\hline 2001 & 2 & 20 & $\mathrm{e}$ & 68.9 & 56.2 & & 26.4 & 49.65 & 14.09 \\
\hline 2001 & 2 & 21 & $\mathrm{n}$ & 311.8 & 279.3 & 166.6 & 12.3 & 49.11 & 13.93 \\
\hline 2001 & 2 & 23 & $\mathrm{e}$ & 53.4 & & & 20.8 & & \\
\hline 2001 & 2 & 24 & $\mathrm{e}$ & 63.8 & 80.8 & 73.3 & 12.1 & 49.77 & 14.95 \\
\hline 2001 & 2 & 25 & $\mathrm{e}$ & 64.4 & 85.5 & 76.5 & 15 & 49.89 & 14.76 \\
\hline 2001 & 2 & 26 & $\mathrm{e}$ & & & 100.5 & 11.9 & 49.99 & 14.85 \\
\hline 2001 & 2 & 27 & $\mathrm{n}$ & & & 277.8 & 7.8 & 49.86 & 14.81 \\
\hline
\end{tabular}




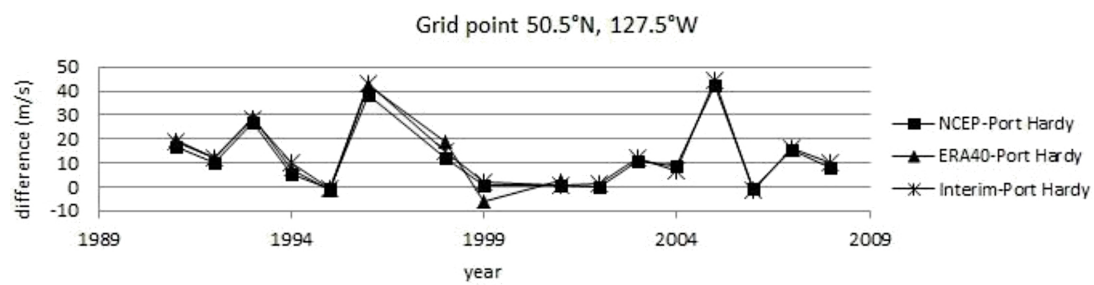

Fig. 7. Differences in February average wind speeds between reanalysis at the grid point of ERA-Interim $49.5^{\circ} \mathrm{N}, 127.5^{\circ} \mathrm{W}$ and Port Hardy station, at $10 \mathrm{hPa}$.
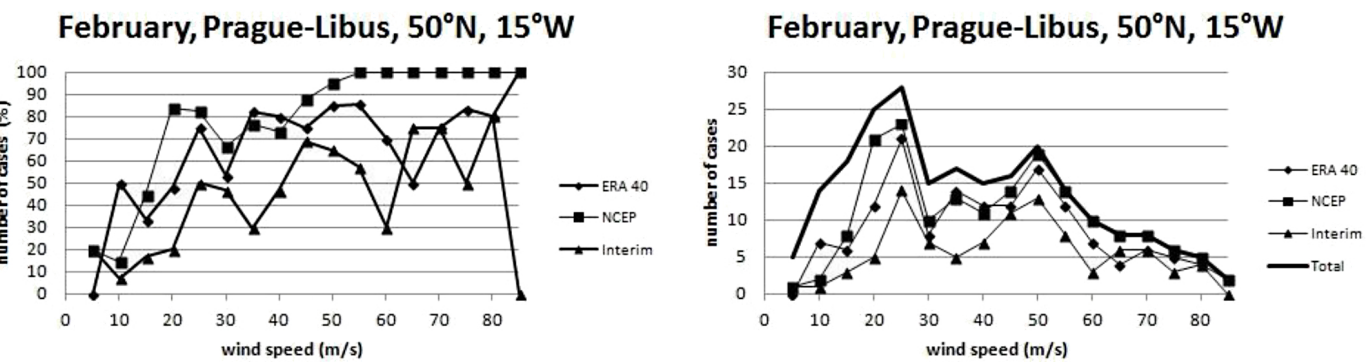

February, Prague-Libus $50^{\circ} \mathrm{N}, 15^{\circ} \mathrm{W}$

February, Prague-Libus $50^{\circ} \mathrm{N}, 15^{\circ} \mathrm{W}$
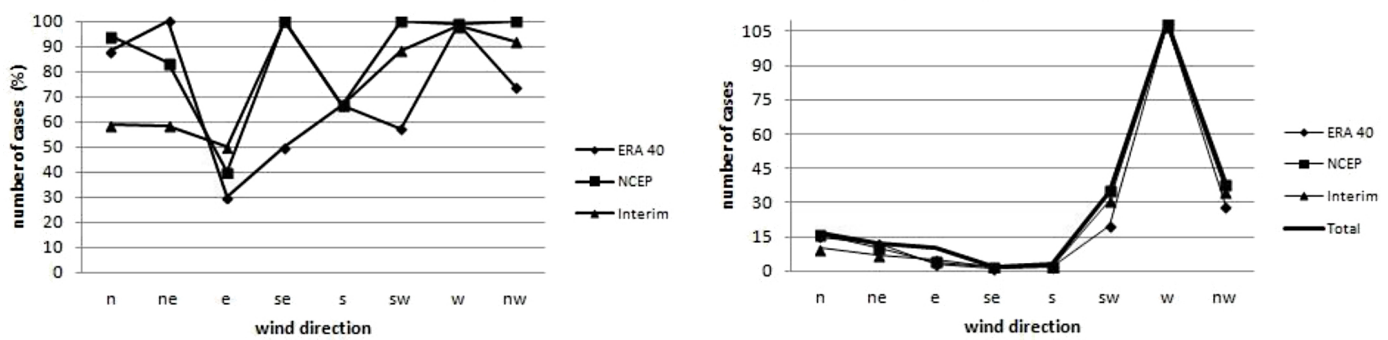

Fig. 8. Number of cases in which the difference between the reanalysis and the Prague-Libus station for wind speed is smaller than $15 \%$ (top panel), or for wind direction is smaller than $45^{\circ}$ (bottom panel) at $10 \mathrm{hPa}$. Left panels are in $\%$, right panels show the number of cases.

Table 2. Outliers (difference between reanalysis and Prague wind directions more than $45^{\circ}$ ) for all three reanalyses at $10 \mathrm{hPa}$ for different wind sectors as observed in Prague. "True" outliers (without ERA-40 1998/1999-2001/2002 winter outliers) are shown in brackets where their number differs from all outliers.

\begin{tabular}{lrrrrr}
\hline Sector & All outliers & NCEP/NCAR & ERA-Interim & ERA-40 & All days \\
\hline $\mathrm{N}$ & 7 & 1 & 7 & 2 & 17 \\
$\mathrm{NE}$ & 5 & 2 & 5 & 0 & 12 \\
$\mathrm{E}$ & $10(9)$ & 6 & 5 & $7(6)$ & 10 \\
$\mathrm{SE}$ & $1(0)$ & 0 & 0 & $1(0)$ & 2 \\
$\mathrm{~S}$ & $2(1)$ & 1 & 1 & $1(0)$ & 3 \\
$\mathrm{SW}$ & $16(4)$ & 0 & 4 & $15(3)$ & 35 \\
$\mathrm{~W}$ & 2 & 1 & 2 & 1 & 109 \\
$\mathrm{NW}$ & $11(3)$ & 0 & 3 & $10(2)$ & 38 \\
all & $54(30)$ & 11 & 27 & $37(14)$ & $\mathbf{2 2 6}$ \\
\hline
\end{tabular}

from $0(1991,1992,1996)$ to $13(2000)$. This means that in February 2000 most days with successful balloon sounding reveal outliers. ERA-Interim outliers are distributed quasiuniformly over the period 1989-2001 with enhanced occurrence in 1994, 2000 and 2001, whereas ERA-40 evidently dominates in outliers since 1998. Table 1 show that ERA40 has only 4 out of 37 outliers before 1998, i.e. before 1998 ERA-40 has a lower occurrence frequency of outliers than NCEP/NCAR and ERA-Interim, whereas in 1998-2001 ERA-40 reveals a much higher occurrence frequency of outliers than the two other reanalyses. For all outlier days, the associated wind speeds vary between 3.1 and $85.9 \mathrm{~m} \mathrm{~s}^{-1}$, with a median value of $20.3 \mathrm{~m} \mathrm{~s}^{-1}$; for NCEP/NCAR, with the smallest number of outliers, the wind speed varies between 3.1 and $59.5 \mathrm{~m} \mathrm{~s}^{-1}$, with a median of $12.3 \mathrm{~m} \mathrm{~s}^{-1}$. Thus outliers occur predominantly with weaker winds (weaker than $30 \mathrm{~m} \mathrm{~s}^{-1}$ ), but they can occur even with very strong winds.

Table 2 presents the distribution of outliers according to wind direction sectors as observed in Prague. For the reanalysis with the lowest number of outliers, NCEP/NCAR, 6 out of 11 outliers occur in the "minor" E sector, i.e. more than $50 \%$ of all outliers. Together with other minor sectors N, NE and $\mathrm{S}, 10$ out of 11 outliers occur in minor sectors. In major sectors W, NW and SW, where 182 out of 226 days occur, NCEP/NCAR has only one outlier. For ERA-Interim, 18 out 
ERA-40

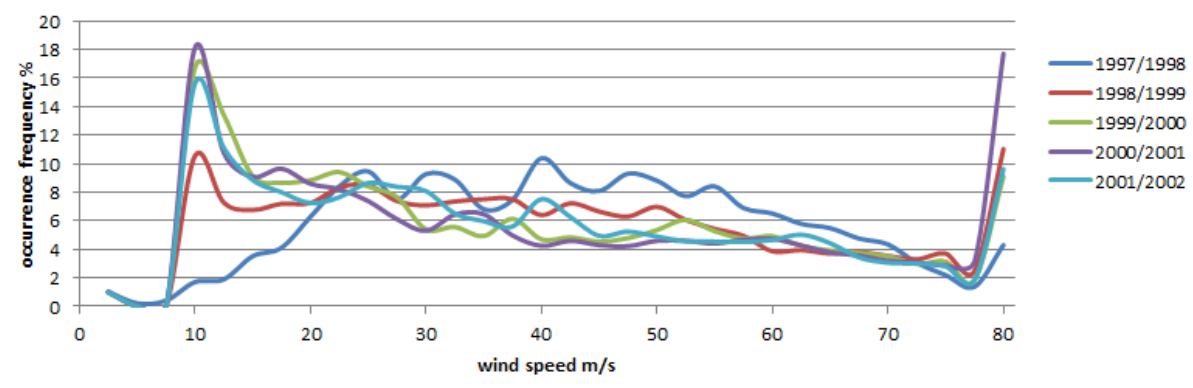

ERA-Interim

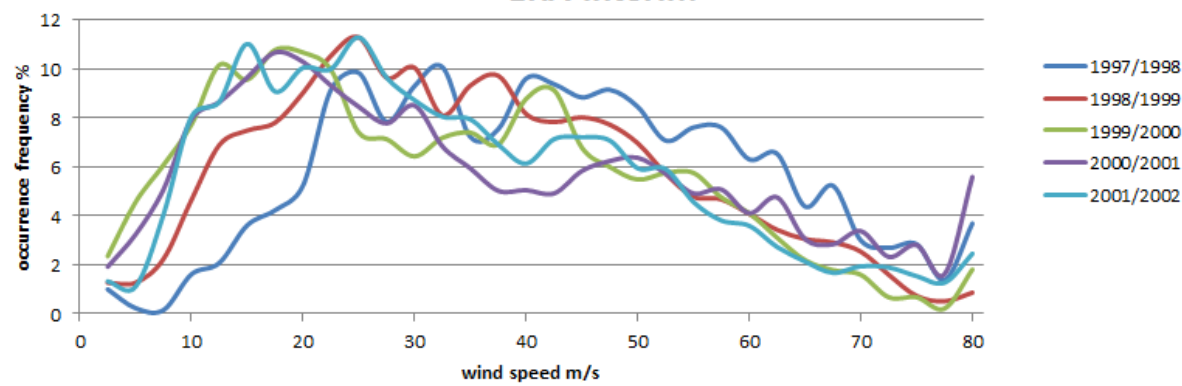

Fig. 9. Wind speed of ERA-40 (top) and ERA-Interim (bottom) for $52.5^{\circ} \mathrm{N}$, sector $0-90^{\circ} \mathrm{E}, 10 \mathrm{hPa}$, for the winters of $1997 / 1998$ to 2001/2002. High values at $80 \mathrm{~m} \mathrm{~s}^{-1}$ are the sum of all speeds $\geq 80 \mathrm{~m} \mathrm{~s}^{-1}$.

of 27 outliers occur in minor sectors and only 9 in major sectors, i.e. minor sectors again dominate. On the other hand, ERA-40 has 26 out of 37 outliers in major sectors and only 11 in minor sectors. However, this distribution may be affected by the peculiar, and rather questionable, huge increase in ERA-40 outlier occurrence in 1998-2001, which occurred essentially in the NW and SW sectors. NCEP/NCAR and ERA-Interim reveal a clear dominance of outlier occurrence in minor sectors.

\subsection{Problems of ERA-40 in its last four years}

The results of tables 1 and 2 indicate a possible problem with the last few years of ERA-40. In the period 1998-2001 (but not for 1989-1997) in Februaries ERA-40 seems to be very different from the other two reanalyses, mainly in the major sectors (NW, W, SW); not the W sector, as in the case of the other reanalyses, but the SW sector dominates. This result is shown in Table 3, where we can see the occurrence frequency of the NW, W, and SW directions in the European sector for all days of radiosonde measurements for the last five winters (1997-2002). While in the winter of 1997/1998 all three reanalyses agree quite well (the $\mathrm{W}$ sector is dominant in winter) and display the standard pattern of W-sector dominance like in previous winters, in the following winters (1998/1999 2001/2002) there are big differences between ERA-40 and the two other reanalyses; the pronounced maximum of occurrence frequency moves from the otherwise dominant $\mathrm{W}$ to SW sector for ERA-40. This means substantially different partition of the total wind into zonal and meridional components.

For wind speed we can see a similar problem as for direction. Figure 1 reveals a larger difference between ERA40 and NCAP/NCAR at $10 \mathrm{hPa}$ for more recent years, which could be explained by problems in the last four years of ERA40. Figures 3 and 4 clearly indicate that the problem of the last four years is observed at $10 \mathrm{hPa}$ but not at $100 \mathrm{hPa}$. It is caused by substantially stronger winds in ERA-40 than in the other two reanalyses and is even more pronounced in summer months than in winter months. In Fig. 9 we present wind speeds from ERA-40 and ERA-Interim separately for the winters of 1997/1998 to 2001/2002. An evident big difference between the winter of 1997/1998 and the following winters appears in the ERA-40 wind speed distribution. The distribution during the first winter is very flat and similar to ERA-Interim, and the maximum can be found between 25 and $50 \mathrm{~m} \mathrm{~s}^{-1}$, but if we look at the following winters, the maximum is shifted to slower winds of about $10 \mathrm{~m} \mathrm{~s}^{-1}$. In the winter of 1998/1999 the maximum is smaller than in the winters of $1999 / 2000$ to 2001/2002. The behaviour for stronger winds is similar for all winters; 1997/1998 has a slightly higher occurrence frequency than the other winters. The ERA-Interim winter wind speed distribution is similar for all winters. The distribution is again very flat and the maximum can be observed between 15 and $30 \mathrm{~m} \mathrm{~s}^{-1}$. If we compare the winter of $1997 / 1998$ for ERA-40 and ERAInterim, there are no significant differences. The same results as for ERA-Interim can be found for NCEP/NCAR 
Table 3. Occurrence frequency of wind directions (in percentage) for all three reanalyses for the winters (October-March) of 1997 to 2002 in the European sector $\left(52.5^{\circ} \mathrm{N}, 0-90^{\circ} \mathrm{E}\right)$.

\begin{tabular}{lrrrl}
\hline & \multicolumn{3}{c}{ Wind direction } & \\
\cline { 2 - 4 } Reanalysis & SW & W & NW & Winter \\
\hline NCEP & 13.1 & 76.7 & 8.9 & $1997-1998$ \\
Interim & 12.4 & 76.8 & 9.8 & \\
ERA40 & 11.3 & 77.2 & 10.2 & \\
\hline NCEP & 16.3 & 71.7 & 7.2 & $1998-1999$ \\
Interim & 17.8 & 69.6 & 7.6 & \\
ERA40 & 70 & 21.5 & 3.1 & \\
\hline NCEP & 6.5 & 75.2 & 9.5 & $1999-2000$ \\
Interim & 4.9 & 74.5 & 11.5 & \\
ERA40 & 58.4 & 27.5 & 4.9 & \\
\hline NCEP & 16 & 59.2 & 11.8 & $2000-2001$ \\
Interim & 15.4 & 58.2 & 12.9 & \\
ERA40 & 57.9 & 22.5 & 5.3 & \\
\hline NCEP & 9.1 & 72.7 & 11.3 & $2001-2002$ \\
Interim & 9.5 & 71.8 & 12.4 & \\
ERA40 & 62.9 & 24.7 & 5.5 & \\
\hline
\end{tabular}

reanalysis. Thus the distribution of wind speeds confirms ERA-40 problems in years 1998-2001.

The combination of the results of Table 3 and Figs. 4 and 9 shows us that between the winters of 1997/1998 and 1998/1999 and/or years 1997 and 1998 the quality of ERA40 stratospheric wind data at $10 \mathrm{hPa}$ evidently decreased. The shift in the maximum in wind speed distribution (occurrence frequency reached up to $20 \%$ at $10 \mathrm{~m} \mathrm{~s}^{-1}$ ) coincides in time with the marked change in the dominant sector from W (1997/1998) to SW (1998/1999-2001/2002). ERA-40 average wind speeds evidently deviate in the years 1998-2001 (Fig. 4). All these above results indicate that ERA-40 stratospheric wind data quality at $10 \mathrm{hPa}$ rapidly decreased since the winter of 1998/1999, and this problem of course influenced the results in Fig. 1. As we can observe in Fig. 1, the agreement between wind speed of NCEP/NCAR and ERA40 is worse in the period 1990-2001 than in the period 19581989 as a consequence of ERA-40 problems. This problem does not occur at the 100 or $500 \mathrm{hPa}$ pressure level; it occurs only at $10 \mathrm{hPa}$. The input data problem is not probable because ERA-Interim uses the same data as ERA-40 for 1998-2002 and we do not observe the same problem in ERAInterim. The origin of the problem with quality of the most recent $10 \mathrm{hPa}$ ERA-40 wind data remains unknown.

\subsection{Effect of radiosonde displacement}

We have to note that data from sounding balloons at $10 \mathrm{hPa}$ are not available for some days of sounding because sounding balloons do not reach this pressure level in some flights.

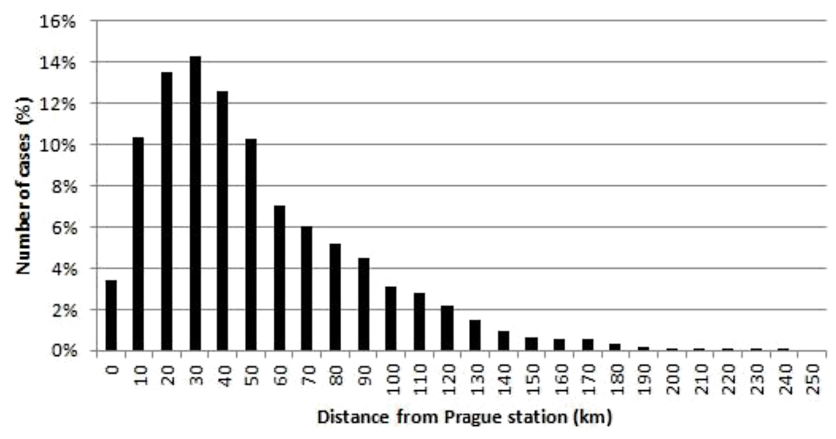

Fig. 10. Distribution of horizontal distance of radiosonde from the Prague station in $10 \mathrm{hPa}$ (irrespective of wind direction) for the winters of 2005 to 2011.

Wind directions in the stratosphere usually do not change much with altitude. As a consequence of that fact, the radiosonde is horizontally displaced from the position of the sonde launching. The effect is relatively small at $100 \mathrm{hPa}$ but it might be quite substantial at $10 \mathrm{hPa}$. Figure 10 shows that the drift-induced shift of a sounding balloon from the Prague station (winter months of the 2005-2011 period) at the $10 \mathrm{hPa}$ level peaks at a distance of about $30 \mathrm{~km}$. If we compare distances from Fig. 10 to the distance between two grid points at $50^{\circ} \mathrm{N}\left(2.5^{\circ}\right.$ in longitude corresponds to $179 \mathrm{~km}$, in latitude to $278 \mathrm{~km}$ ), we can say that the sonde drift in most cases does not make a problem, but sometimes the horizontal shift of the sonde could influence the comparison of soundings with reanalysis; on the other hand, the difference between the state of the stratosphere in the two neighbour grid points is mostly rather small, thus even larger sonde shifts should mostly have rather little effect on the comparison of sounding with reanalysis.

Prague-Libus is located just in the grid point $50^{\circ} \mathrm{N}, 15^{\circ} \mathrm{E}$. Table 1 shows the position of sonde at $10 \mathrm{hPa}$ for all outlier days, except for days in 1998-2001, when outliers occur only for ERA-40, as in view of the above analysis these outliers are rather artifacts due to problems with the reliability of ERA-40 wind directions. We define a "true" outlier as an outlier which is not affected by the 1998-2001 period ER-40 problem. Only 30 "true" outliers remain for comparison with sonde position.

The displacements in latitude are small, often negligible. For ERA-40 and NCEP/NCAR the grid point latitude closest to the sonde position is always latitude $50^{\circ} \mathrm{N}$ used in the above comparison. For ERA-Interim in 28 out of 30 cases the closest grid point latitude is $49.5^{\circ} \mathrm{N}$ used in comparisons; only in two cases is the next latitude, $51^{\circ} \mathrm{N}$, slightly closer to the sonde position, but for these days $50^{\circ} \mathrm{N}$ is the closest latitude. Shifts in longitude are slightly larger but none of them is larger than $1.25^{\circ}$, i.e. for ERA-40 and NCEP/NCAR the closest grid point longitude to sonde position is always $15^{\circ} \mathrm{E}$. For ERA-Interim, in three cases the closest grid point 
longitude is $13.5^{\circ} \mathrm{E}$; in the remaining 27 cases the closest grid longitude is $15^{\circ} \mathrm{E}$.

Summarising we can say that in all "true" outlier days for ERA-40 and NCEP/NCAR and for the large majority of ERA-Interim days the grid point used in analysis $\left(50^{\circ} \mathrm{N}\right.$, $15^{\circ} \mathrm{E}$ ) is the closest grid point to sonde position at $10 \mathrm{hPa}$. Moreover, as Fig. 5 illustrates for ERA-Interim, the difference in winds at two neighbour grid points is usually rather small. Thus the displacement of the sonde position due to drift generally does not have a significant effect on our outlier analysis.

\subsection{Sectorial distribution of outliers}

Table 2 shows that for the dominant $\mathrm{W}$ sector with 109 days, outliers occur only on two days. This means that there is good agreement for wind direction between reanalyses and Prague observations for the dominant wintertime wind direction sector. On the other hand, all 10 days in the E sector reveal outliers in at least one reanalysis, and 9 of them reveal "true" outliers. This sector is the source of more than $50 \%$ of outliers for NCEP/NCAR. Also, the N and NE sectors show a high occurrence frequency of outliers $(\sim 40 \%)$. In two other minor sectors, $\mathrm{S}$ and SE, winds in Februaries hardly ever occur ( 2 and 3 days). If we consider only "true" outliers, 23 out of 30, i.e. the large majority, occur in "minor" sectors, whereas only 7 outliers occurred in the major $\mathrm{NW}, \mathrm{W}$, and SW sectors, where wind is located for more than $90 \%$ of the days.

\subsection{Influence of selected meteorological phenomena}

How do different meteorological phenomena influence wind in the stratosphere? We selected NAO (North Atlantic Oscillation) and sudden stratospheric warming (SSW) for comparison with the February outlier occurrence. NAO is considered as January and February monthly values. However, the dominance of the positive phase of NAO, particularly in Februaries, is so prevalent (Table 4 - out of 13 , only two display negative phase, and very weakly) that the dependence on the phase of NAO cannot be investigated with this data set due to the practical absence of the negative phase of NAO.

The stratosphere in February at high latitudes is under strong influence of SSW, and this influence in some years significantly affects the stratosphere at higher middle latitudes, including latitudes around $50^{\circ} \mathrm{N}$ (Prague). If we consider only "true" NCEP/NCAR and ERA-Interim outliers, there are four years with enhanced occurrence of outliers, 1989, 1994, 2000 and 2001. In 1989 and 1994 the vortex was split by SSWs, in 2001 the vortex was weak due to SSWs and only in 2000 was the vortex well developed due to a very cold winter. For NCEP/NCAR, 8 out of 11 outliers occurred in the three years with a very disturbed vortex in February - 1989, 1994 and 2001. For ERA-Interim, 15 out of 27 outliers occurred in these three years. Even though in 1991, also
Table 4. NAO index for January and February, respectively and information about stratospheric warming and/or state of polar vortex in February, 1989-2001.

\begin{tabular}{rrl}
\hline Year & NAO & Stratwarm in Feb \\
\hline 1989 & $1.17,2.00$ & Major splitting \\
1990 & $1.04,1.41$ & No major \\
1991 & $0.86,1.04$ & Major end of Jan \\
1992 & $-0.13,1.07$ & Minors in Feb \\
1993 & $1.60,0.50$ & Strong minor in Feb - impact in Europe \\
1994 & $1.04,0.46$ & Vortex split in Feb - impact in Europe \\
1995 & $0.93,1.14$ & Strong minor in Feb - displaced toward Siberia \\
1996 & $-0.12,-0.07$ & Coldest winter on record \\
1997 & $-0.49,1.70$ & Strong and cold vortex \\
1998 & $0.39,-0.11$ & Slightly disturbed vortex \\
1999 & $0.77,0.29$ & Very weak and disturbed vortex \\
2000 & $0.60,1.70$ & Very cold winter \\
2001 & $0.25,0.45$ & Weak vortex \\
\hline
\end{tabular}

affected by major warming, no outlier was observed, we can say that there is a tendency of outliers to occur more often in years with a substantially disturbed and weak vortex.

\section{Discussion}

We have made a simple comparison of three reanalyses, NCEP/NCAR-1, ERA-40 and ERA-Interim, without applying advanced statistical methods. Detailed comparison has been made for $52.5^{\circ} \mathrm{N}$ and $50^{\circ} \mathrm{N}$, but other northern extratropical latitudes have also been briefly mentioned. We observe some significant differences among these three reanalyses. Winter season (October-March) averages reveal some differences, particularly at $10 \mathrm{hPa}$ before 1965 , when ERA40 provided average winds higher by $5 \mathrm{~m} \mathrm{~s}^{-1}$ and more than NCEP/NCAR (Fig. 2).

Figures 3 and 4 show significant differences between NCEP/NCAR and ERA-40 at $10 \mathrm{hPa}$ mainly at the beginning of the period and surprisingly even more in the last four ERA-40 years. We have to note that satellite data were assimilated only from 1979 . Our results can provide some hints where the problem with the last ERA-40 years since 1998 could be. As mentioned before, the problem occurs year round. The agreement is good for all three reanalyses in summer except for the last four years of ERA-40. We can hardly speculate that the origin of the differences comes from the different stratospheric dynamic parts in each reanalysis because the difference has not been observed at the $100 \mathrm{hPa}$ level. At $100 \mathrm{hPa}$ a good agreement is found for all three reanalyses (Fig. 3) both in summer and winter for the whole analysed period. In the winter stratosphere, especially in January and February, the SSWs occur and the different representations of this phenomenon in assimilation process (Berrisford et al., 2009; Dee et al., 2011; and Uppala et al., 2005) could partly contribute these differences; however, in 1998-2001 the differences are more pronounced in summer. 
The differences between reanalyses can be caused by several reasons. The first one could be the processing of the original observational data. According to Birner (2010) the assimilation of satellite radiance is different for ECMWF and NCEP/NCAR reanalysis. ECMWF assimilate these measurements directly, but NCEP/NCAR convert them into temperature and then they are assimilated into the model. This could affect the results to some extent, but probably not much. Furthermore, data assimilation has been shown to act to smooth the vertical temperature structure around the tropopause as well. Another problem could be the different vertical resolution in the stratosphere. According to Uppala et al. (2005) and Berrisford et al. (2009), the vertical resolution of ERA-40 and ERA-Interim is 37 pressure levels up to $0.1 \mathrm{hPa}$, while NCEP/NCAR reanalysis (Kistler et al., 2001) has a different vertical resolution for the stratosphere (28 levels up to $2.7 \mathrm{hPa}$ ). That is why there are fewer pressure levels between the top of the model and $10 \mathrm{hPa}$ for NCEP/NCAR. This could contribute to differences between NCEP and ECMWF reanalysis, especially at the beginning of the period, but our finding that the least number of wind direction outliers is observed for NCEP/NCAR rather contradicts a significant role of vertical resolution. The main differences between ERA-40 and ERA-Interim are the assimilation process (i.e. 3D-Var for ERA-40 and 4D-Var for ERA-Interim) with possible impact on differences between reanalyses. According to Dee et al. (2011) there is a problem with assimilation of the ozone profile into ERA-Interim reanalysis, which systematically caused large and unrealistic changes in temperature and winds near the top of the model. This behaviour is not caused by input data for reanalyses, as they are almost equal (equal for ECMWF reanalyses).

Mutual comparison of reanalyses does not answer the question of which reanalysis is more consistent with observational data. For this purpose three stations, Prague-Libus, Port Hardy and Valentia, were selected for comparison of daily values of in situ radiosonde sounding measurements of winds with reanalysis.

Figure 5 confirms our suggestion that the larger differences between reanalyses and Prague sonde observations occur mainly in the winter half of the year. Figure 7 demonstrates that some stations like Port Hardy (or Valentia) show much worse results of comparison than the Prague station, and we cannot recommend these stations for comparison with and testing of reanalyses of stratospheric winds.

Figure 8 shows clearly that the problem with outliers in wind direction in Februaries at $10 \mathrm{hPa}$ is caused mainly by "minor" wind directions (easterly), whereas major directions (westerly) show good agreement except for ERA-40. The preference of outlier occurrence (days where the wind direction difference is larger than $45^{\circ}$ ) in "minor sectors" is clearly documented in Table 2. It is evident that ERA-Interim and NCEP/NCAR have problems with wind direction determination for minor wind directions (E, NE and N) as measured at Prague-Libus, whereas major wind directions (SW,
$\mathrm{W}$, and NW) are determined correctly. In Table 1 and the related discussion we consider the possible effect of radiosonde drift in terms of radiosonde position at $10 \mathrm{hPa}$ with respect to Prague-Libus. Fortunately the results on outlier days are not significantly influenced by radiosonde drift.

Table 1 shows the outlier days to occur in most years of the period 1989-2001, with a different distribution for each reanalysis. ERA-Interim has more than twice as much outlier occurrence than NCEP/NCAR, which appears to agree best with Prague observations from the point of view of outliers. ERA-40 has remarkably more outliers than the other two reanalyses, but its outliers must be divided into two groups. Before 1998 ERA-40 has the smallest occurrence frequency of outliers among the three reanalyses, whereas in 1998-2001 ERA-40 reveals many more outliers than the two other reanalyses, and these outliers occur essentially in two "major" sectors, SW and NW, contrary to the behaviour of the other two reanalyses, indicating a potential ERA-40 output problem.

Various results of this paper clearly indicate problems with the quality and reliability of the ERA-40 $10 \mathrm{hPa}$ wind data series in the last four years 1998-2001 (2002). Figure 1b reveals a larger difference between ERA-40 and NCEP/NCAR for more recent data in distribution of wind speeds. Figure 4 localises this difference into the last four years 1998-2001. Figure 9 shows that the winters of $1998 / 1999$ to 2001/2002 exhibit an anomalous sharp maximum at a wind speed of $10 \mathrm{~m} \mathrm{~s}^{-1}$. Table 3 shows that the ERA- 40 wind direction distribution in the winter of $1997 / 1998$ is quite similar to that of NCEP/NCAR and ERA-Interim, with a sharp maximum in the W sector, whereas in the winters of 1998/1999 to 2001/2002 this sharp maximum in ERA-40, not in the other two reanalyses, moved anomalously to the SW sector, where the zonal and meridional components of wind are comparable. The list of wind direction outliers in Table 1 shows that the large majority of ERA-40 outliers occur in the last four years. Therefore we recommend not using ERA-40 $10 \mathrm{hPa}$ wind data from the winters of 1998/1999 to 2001/2002 or using them only very carefully, taking into account the above problems. The problem does not occur at the 100 or $500 \mathrm{hPa}$ pressure levels. We are afraid that explanation of this problem can be provided only by those who prepared ERA- 40 data in this period.

\section{Conclusions}

The main conclusions of this study of stratospheric winds at the 10 and $100 \mathrm{hPa}$ levels (predominantly at higher middle latitudes) are as follows:

1. The quality of the ERA- 40 reanalysis $10 \mathrm{hPa}$ winds evidently decreases for years 1998-2001 (2002). This problem occurs for $10 \mathrm{hPa}$ only; at $100 \mathrm{hPa}$ we did not identify such a problem. The change in the dominant 
wind directions means a larger meridional component compared with previous years.

2. Large differences between reanalysis and Prague observations in the February $10 \mathrm{hPa}$ wind direction (larger than $45^{\circ}$ - outliers) occur predominantly when winds in Prague are in "minor" sectors N, NE and E, whereas "major" sectors, particularly the dominant $\mathrm{W}$ (westerly) wind sector, exhibit only a few outliers with such a large difference (at least for NCEP/NCAR and ERA-Interim). This finding can serve as a hint for detecting the problem in reanalysis.

3. NCEP/NCAR agrees better with Prague radiosonde balloon observations than ERA-40 and ERA-Interim. However, if the winters of 1998/1999-2001/2002 are removed, ERA-40 agrees best with Prague observations, because the large majority of ERA-40 outliers occurred in these four winters.

4. There is a tendency to higher occurrence frequency of outliers in the winters with a weak and disturbed polar vortex.

The above results are based on data from latitudes 50 $52.5^{\circ} \mathrm{N}$, but the results for other latitudes show that the results change with latitude $\left(32.5-72.5^{\circ} \mathrm{N}\right)$ only quantitatively, not qualitatively. We have made a simple comparison of three reanalyses, but the key result (1) is obtained without doubt.

Acknowledgements. This study was supported by the Charles University grant SVV 2011263308, the GACR grant P209/10/1792 and the Ministry of Education, Health and Sports grant LD 12070. ERA-40 and ERA-Interim reanalysis data were provided by the ECMWF from their website at http://data-portal.ecmwf.int/ and NCEP/NCAR reanalysis data from website http:/www.esrl.noaa. gov/psd. We acknowledge the provision of Prague radiosonde data by the Czech Hydrometeorological Institute (CHMI). We thank M. Motl of CHMI for providing radiosonde drift data for outlier dates. Data for stations Port Hardy and Valentia are taken from the website http://www1.ncdc.noaa.gov/pub/data/igra/derived/.

Topical Editor C. Jacobi thanks two anonymous referees for their help in evaluating this paper.

\section{References}

Akperov, M. G. and Mokhov, I. I.: A comparative analysis of the method of extratropical cyclone identification, Izvestiya, Atmos. Ocean. Phys., 46, 574-590, 2010.

Berrisford, P., Dee, D., Fielding, K., Fuentes, M., Kallberg, P., Kobayashi, S., and Uppala, S.: The ERA-Interim Archive, ERA Report Series. 1. Technical Report. European Centre for Medium-Range Weather Forecasts, Shinfield Park, Reading, 2009.

Birner, T.: Recent widening of the tropical belt from global tropopause statistics: Sensitivities, J. Geophys. Res., 115, D23109, doi:10.1029/2010JD014664, 2010.
Brönnimann, S., Stickler, A., Griesser, T., Fischer, A.M., Grant, A., Ewen, T., Zhou, T., Schraner, M., Rozanov, E., and Peter, T.: Variability of large-scale atmospheric circulation indices for the northern hemisphere during the past 100 years, Meteorol. Z., 18, 379-396, 2009.

Courtier, P., Andersson, E., Heckley, W., Vasiljevic, D., Hamrud, M., Hollingsworth, A., Rabier, F., Fisher, M., and Pailleux, J.: "The ECMWF Implementation of Three Dimensional Variational Assimilation 3D-Var. Pt I: Formulation, Q. J. Roy. Meteorol. Soc., 124, 1783-1808, 1998.

Dee, D. P., Uppala, S. M., Simmons, A. J., Berrisford, P., Poli, P., Kobayashi, S., Andrae, U., Balmaseda, M. A., Balsamo, G., Bauer, P., Bechtold, P., Beljaars, A. C. M., van de Berg, L., Bidlot, J., Bormann, N., Delsol, C., Dragani, R., Fuentes, M., Geer, A. J., Haimberger, L., Healy, S. B., Hersbach, H., Hólm, E. V., Isaksen, L., Kållberg, P., Köhler, M., Matricardi, M., McNally, A. P., Monge-Sanz, B. M., Morcrette, J.-J., Park, B.-K., Peubey, C., de Rosnay, P., Tavolato, C., Thépaut, J.-N., and Vitart, F.: The ERA-Interim reanalysis: configuration and performance of the data assimilation system, Q. J. Roy. Meteorol. Soc., 137, 553597, 2011.

Greatbatch, R. J. and Rong, P. P.: Discrepancies between different northern hemisphere summer atmospheric data products, J. Climate, 19, 1261-1273, 2006.

Iwasaki, T., Hamada, H., and Miyazaki, K.: Comparison of BrewerDobson circulations diagnosed from reanalyzes, J. Meteorol. Soc. Jpn., 87, 997-1006, 2009.

Kalnay, E., Kanamitsu, M., Kistler, R., Collins, W., Deaven, D., Gandin, L., Iredell, M., Saha, S., White, G., Woollen, J., Zhu, Y., Chelliah, M., Ebisuzaki, W., Higgins, W., Janowiak, J., Mo, K. C., Ropelewski, C., Wang, J., Leetmaa, A., Reynolds, R., Jenne R., and Joseph, D.: The NCEP/NCAR 40-Year Reanalysis Project, B. Am. Meteorol. Soc., 77, 437-471, 1996

Kanamitsu, M., Ebisuzaki, W., Woollen, J., Yang, S.-K., Hnilo, J. J., Fiorino, M., and Potter, G. L.: NCEP-DEO AMIP-II Reanalysis (R-2), 1631-1643, B. Atmos. Meteorol. Soc., 2002.

Kistler, R., Kalnay, E., Collins, W., Saha, S., White, G., Woollen, J., Chelliah, M., Ebisuzaki, W., Kanamitsu, M., Kousky, V., van den Dool, H., Jenne, R., and Fiorino, M.: "The NCEP 50-Year Reanalysis: Monthly Means CD-ROM and Documentation, B. Am. Meteorol. Soc., 82, 247-267, 2001.

Lehmann, E. and Nevir, P.: Uncertainties in relative atmospheric angular momentum computed from zonal winds in reanalysis data, J. Geophys. Res., 117, D09101, doi:10.1029/2011JD016658, 2012.

Laštovička, J., Akmaev, R. A., Beig, G., Bremer, J., Emmert, J. T., Jacobi, C., Jarvis, M. J., Nedoluha, G., Portnyagin, Yu. I., and Ulich, T.: Emerging pattern of global change in the upper atmosphere and ionosphere, Ann. Geophys., 26, 1255-1268, doi:10.5194/angeo-26-1255-2008, 2008.

Laštovička, J., Križan, P., and Kozubek, M.: Long-term trends in the middle atmosphere dynamics at northern middle latitudes - one regime or two different regimes?, Atmos. Chem. Phys. Discuss., 10, 2633-2668, doi:10.5194/acpd-10-2633-2010, 2010.

Martineau, P. and Son, S.-W.: Quality of reanalysis data during stratospheric vortex weakening and intensification events, Geophys. Res. Lett., 37, L22801, doi:10.1029/2010GL045237, 2010.

Masaki, Y.: Wind field differences between three meteorological reanalysis data sets detected by evaluating atmospheric 
excitation of Earth rotation, J. Geophys. Res., 113, D07110, doi:10.1029/2007JD008893, 2008.

Onogi, K., Tsutsui, J., Koide, H., Sakamoto, M., Kobayashi, S., Hatsushika, H., Matsumoto, T., Yamazaki, N., Kamahori, H., Takahashi, K., Kadokura, S., Wada, K., Kato, K., Oyama, R., Ose, T., Mannoji, N., and Taira, R.: The JRA-25 Reanalysis, J. Meteorol. Soc. Jpn., 85, 369-432, 2007.

Paek, H. and Huang, H.-P.: A comparison of the interannual variability in atmospheric angular momentum and length-of-day using multiple reanalysis data sets, J. Geophys. Res., 117, D20102, doi:10.1029/2012JD018105, 2012.

Parrish, D. F. and Derber, J. D.: The National Meteorological Center Spectral Statistical Interpolation Analysis System, Mon. Weather Rev., 120, 1747-176, 1992.

Reichle, R. H.: The MERRA-Land Data Product, version 1.1. GMAO Technical Report, NASA Global Modeling and Assimilation Office, Goddard Space Flight Center, Greenbelt, MD, USA, 2012.

Screen, J. A. and Simmonds, I.: Erroneous Arctic Temperature Trends in the ERA-40 Reanalysis: A Closer Look, J. Climate, 24, 2620-2627, 2011.

Simmons, A. J., Jones, P. D., da Costa Bechtold, V., Beljaars, A. C. M., Kållberg, P. W., Saarinen, S., Uppala, S. M., Viterbo, P., and Wedi, N.: Comparison of trends and low frequency variability in CRU, ERA-40, and NCEP/NCAR analyses of surface air temperature, J. Geophys. Res., 109, D24115, doi:10.1029/2004JD005306, 2004.
Trigo, I. F.: Climatology and interannual variability of storm tracks in the Euro-Atlantic sector: a comparison between ERA-40 and NCEP/NCAR reanalyzes, Clim. Dynam., 26, 127-143, 2006.

Uppala, S. M., Kållberg, P. W., Simmons, A. J., Andrae, U., Da Costa Bechtold, V., Fiorino, M., Gibson, J. K., Haseler, J., Hernandez, A., Kelly, G. A., Li, X., Onogi, K., Saarinen, S., Sokka, N., Allan, R. P., Andersson, E., Arpe, K., Balmaseda, M. A., Beljaars, A. C. M., Van De Berg, L., Bidlot, J., Bormann, N., Caires, S., Chevallier, F., Dethof, A., Dragosavac, M., Fisher, M., Fuentes, M., Hagemann, S., Hólm, E., Hoskins, B. J., Isaksen, L., Janssen, P. A. E. M., Jenne, R., Mcnally, A. P., Mahfouf, J.F., Morcrette, J.-J., Rayner, N. A., Saunders, R. W., Simon, P., Sterl, A., Trenberth, K. E., Untch, A., Vasiljevic, D., Viterbo, P., and Woollen, J.: The ERA-40 Re-Analysis, Q. J. Roy. Meteorol. Soc., 131, 2961-3012, 2005.

Watarai, Y. and Tanaka, H. L.: Characteristics of the JRA-25 dataset from the viewpoint of global energetics, SOLA, 3, 9-12, 2007.

Žagar, N., Tribbia, J., Anderson, J., and Raeder, K.: Uncertainties of estimates of inertio-gravity energy in the atmosphere. Part I: Intercomparison of four analysis systems, Mon. Weather Rev., 137, 3837-3857, 2009.

Zhao, Y. and Li, J.: Discrepancy of mass transport between the Northern and Southern hemispheres among the ERA-40, NCEP/NCAR, NCEP-DOE AMIP-2, and JRA-25 reanalysis, Geophys. Res. Lett., 33, L20804, doi:10.1029/2006GL027287, 2006. 